\title{
A practical representation of NFT pedagogy in a learning environment
}

\section{Dr Nisi Thusi ${ }^{1 *}$ Dr King Costa ${ }^{1}$}

${ }^{1 *}$ School of Business and Economics, Department of Commercial Accounting, University of Johannesburg, South Africa

1 Global Centre for Academic Research, Johannesburg, South Africa

\section{INTRODUCTION}

Advanced pedagogy is the way to enhance teaching and learning performance for non-financial students. There are different methods in use across the globe for innovative teaching of higher learning students. The use of multimedia and technology empowers educational processes by increasing interaction between teachers and students. Hybrid teaching and blended learning follow an integrated approach to teaching that blends with students' interests and teacher's personality that needs curriculum appropriate methods. Teachers should thus apply themselves to utilizing innovative methods so that the students' learning process is as free-flowing and that the methodology used creates an atmosphere adaptable to conducive learning environment.

The application of innovative teaching and learning methods is critical if we are to motivate and enculturate a spirit of learning and cooperation by encouraging others and doing your share on the part of students. The role of education is to ensure that while academic personal are involve in active teaching, an effort is made to ensure alignment between what is taught and what is comprehensible in relation to students. The goal of this study is an ongoing and progressive examine of how Edger Dale's Cone of Experience and Bloom's taxonomy is employed to positively influence student learning. In this conceptual research the methodology used was hinged on analytic processes for material already published in this area. Key variables under investigation forecast on integration of Dales and Blooms theories for theoretical perspectives with the researchers pedagogy known as the NFT.

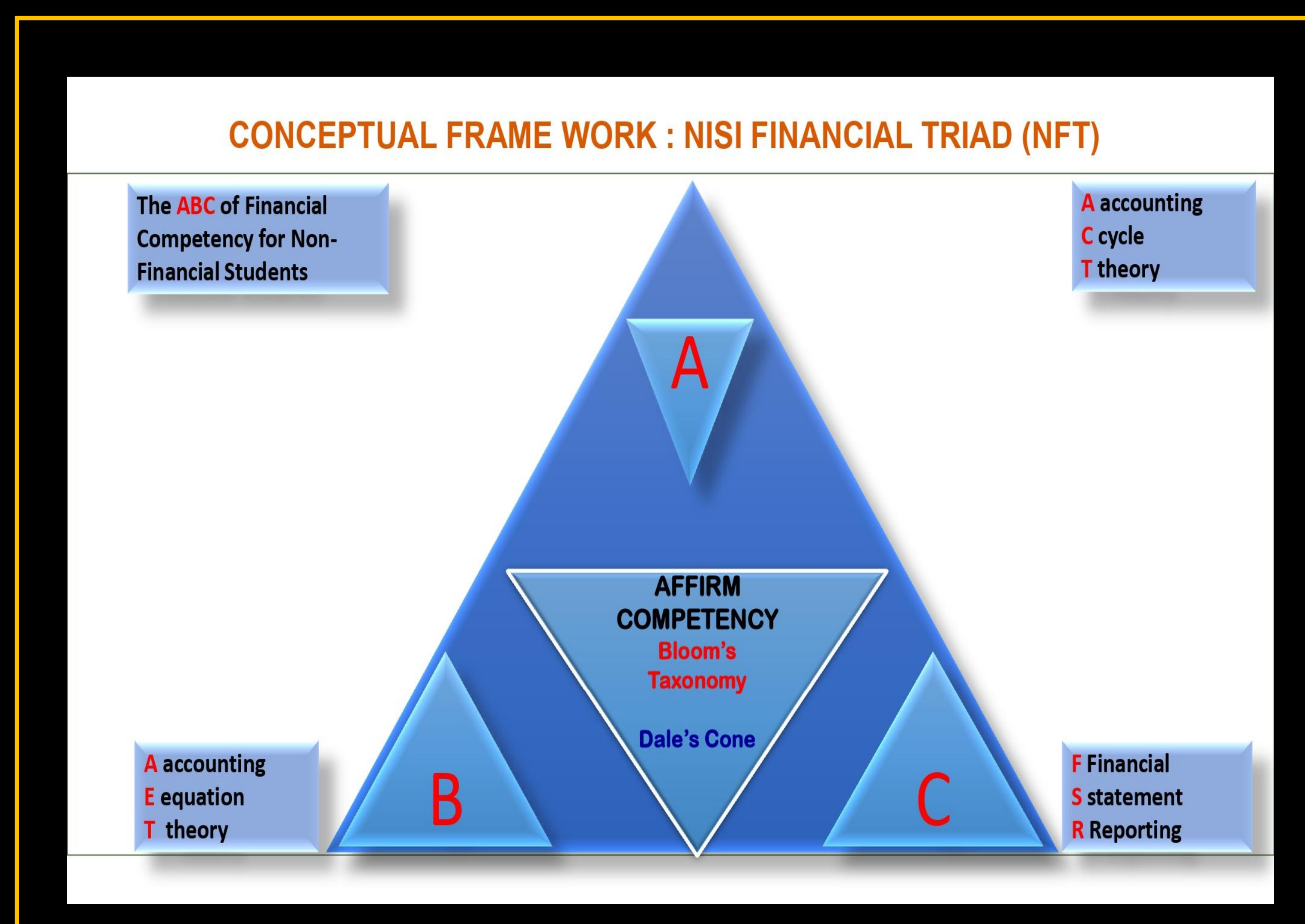

Figure 1: Nisi Financial Triad - an learning instructional for non-financia accounting students

\section{METHODOLOGY}

Researchers conducted an experiential application of Nisi Financial Triad in a academic setting in Johannesburg, South Africa. The application of the NFT integrated Dale's and Bloom's pedagogical instruments in a real life setting where students were observed over a period of 12 months. Figure 3 is a real-time depiction of the NFT in practice, with one of the researchers supervising learning. Limitations to this project are the fact that NFT is novel and has not been implemented beyond the practice of the researchers, making it a research in progress. Students consented to be part of the programme and provided a great feedback in relation to the simplicity yet fundamental instructional dimension aiding their learning absorption.

\section{APPLICATION}

The NFT model for instruction aims to simplify the Applied Accounting Skills module and to have an impact on teaching and learning. This model attempts to combine both theories. Edgar Dale theorized that learners retain more information by what they "do" as opposed to what is "heard", "read" or "observed" According to Bloom's taxonomy, each level of knowledge can correspond to each level of cognitive process, so a student can remember factual or procedural knowledge.
DALE'S CONE OF EXPERIENCE

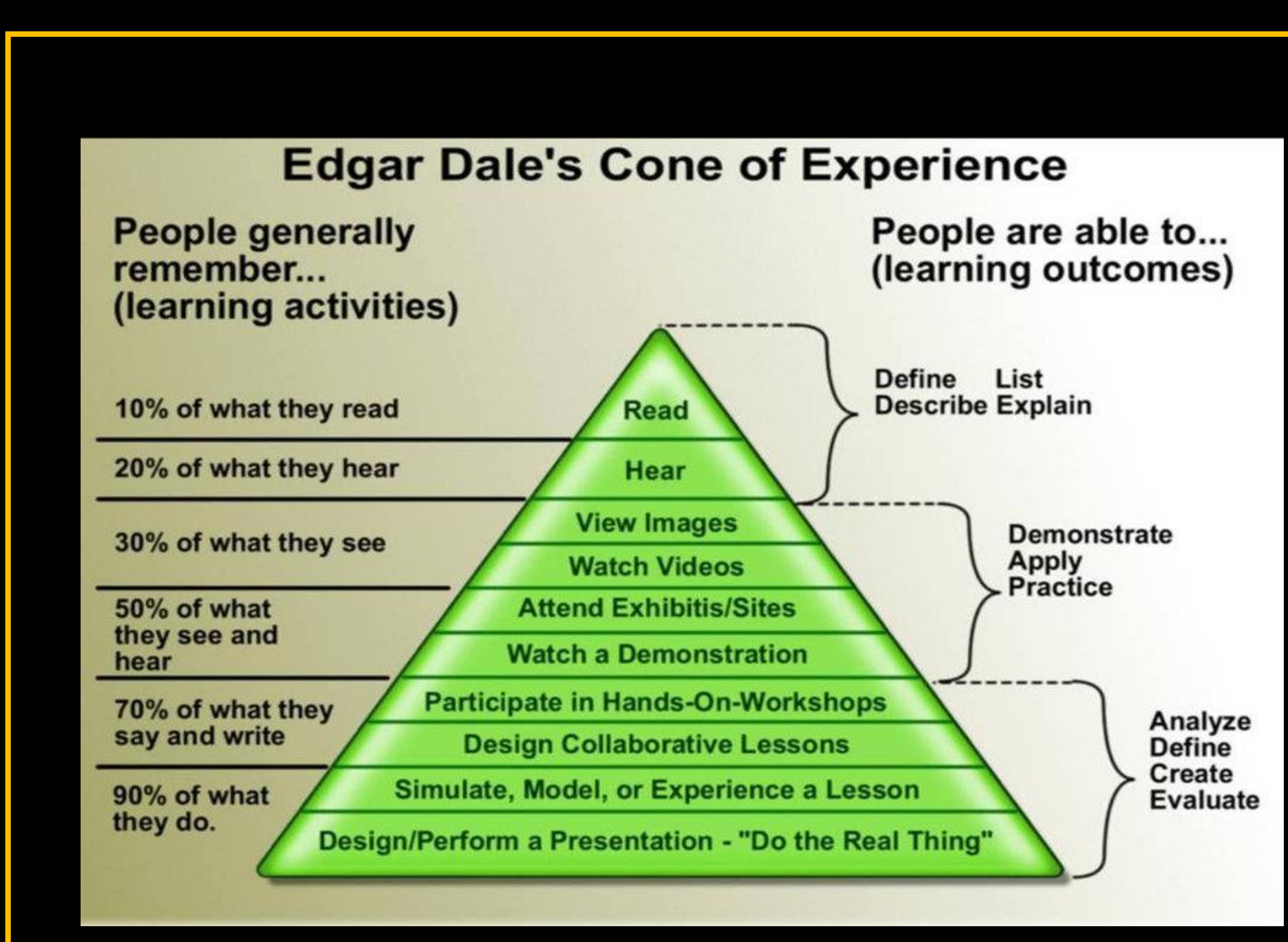

Figure 2: Dale's Cone of Learning Experience
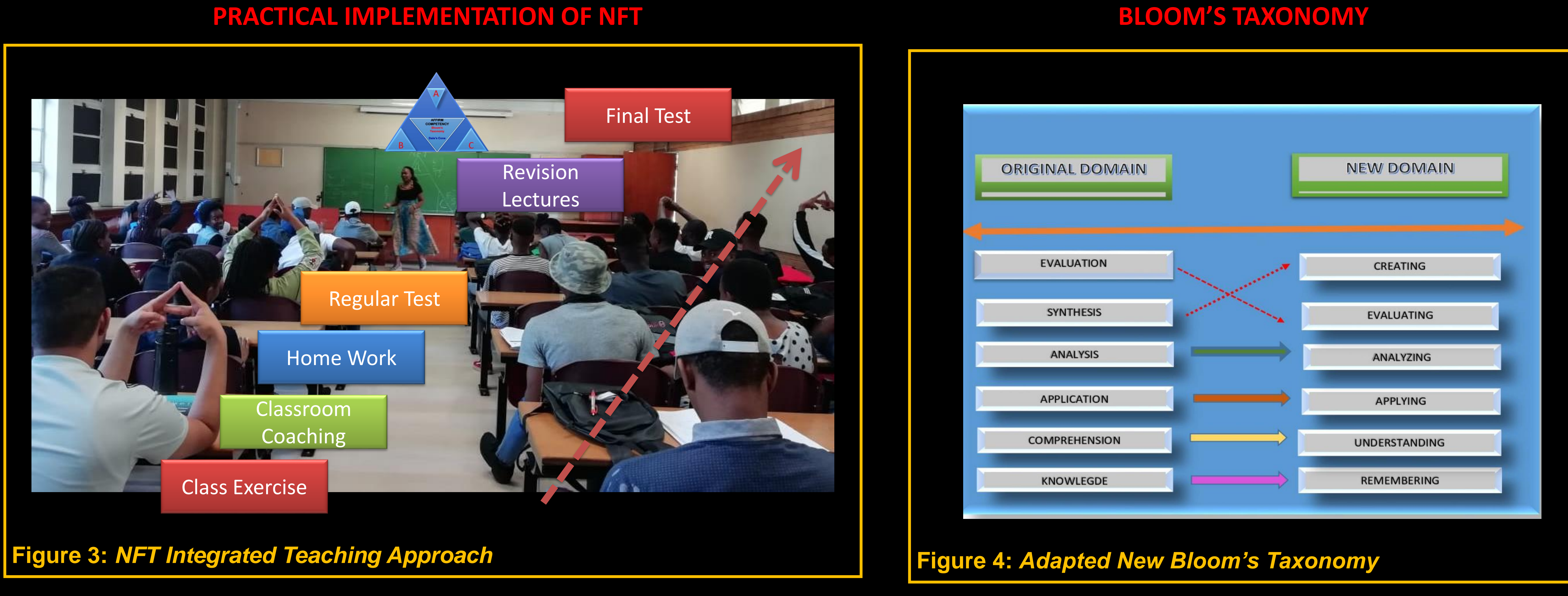

Figure 4: Adapted New Bloom's Taxonomy

\begin{abstract}
NF广-COMPONETS
$\mathbb{A}$

(Accounting Cycle Theory) which is at the top of the model. The student should understand the accounting process in the order in which a transaction that took place, is recorded in the accounting records.
\end{abstract}

(Accounting Equation Theory) which is in the middle of the model Students are provided with the basic principles of accounting, the accounting process, accounting equation and the duality concept of accounting.

(Financial Statements) which is at the bottom and the last of the model. The student should determine the financial position of an entity and the recording of each transaction to the financial

statements of a basic entity of a sole trader as a service entity and a trading entity

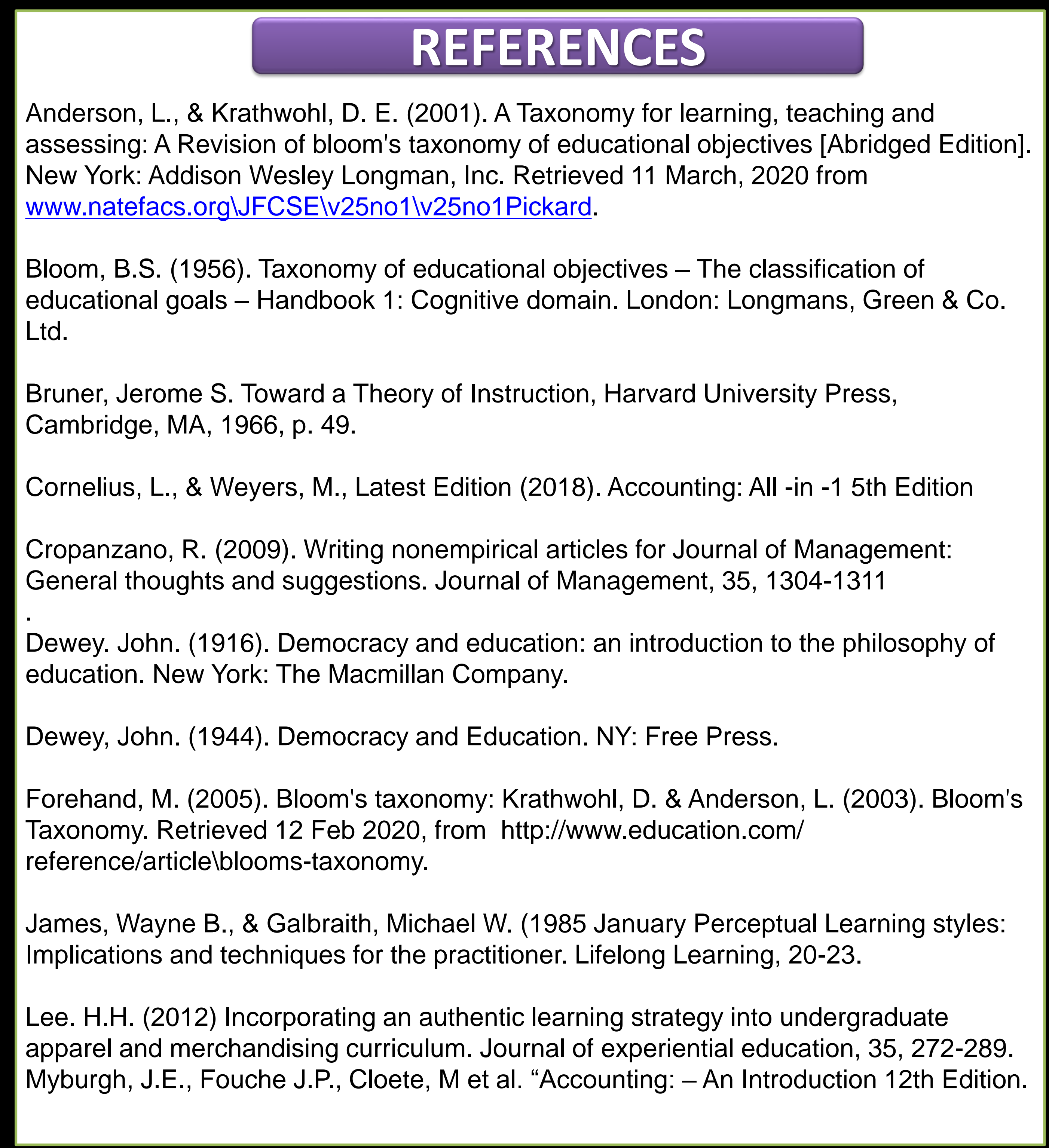

\section{Name : Dr Nisi Thusi}

Affilliation: University of

Johannesburg

Tel no.: (+27)079 2861336

Email: 